\title{
Esquemata en frecuencias. Un cuento ruso
}

\author{
Esquemata at frequencies. A Russian tale
}

\begin{abstract}
ANTONIO ARMENTEROS ÁLVAREZ
Poeta, narrador, traductor y crítico literario. Ha publicado el libro de relatos País que no era (2005) y seis poemarios: Nastraienie (2000), La Caída (2000), Los Estados Crepusculares (2002), Casa Québec (2002), La Cortadura y El Signo (2003) y Kenoma (2014). Su obra ha sido publicada y antologaza en Honduras, Rusia, Suecia, México, Brasil, España, Estados Unidos, Francia, Ecuador y Colombia. Ha obtenido, entre otros premios, el Abdala (1999), el Razón de Ser (2003) , el Premio Dador (2006) y La Gaceta de Cuba (2007).
\end{abstract}

RECIBIDO: 3 DE MARZO DE 2015

ACEPTADO: 8 DE MARZO DE 2015

DOI: 10.7203/KAM.5.4694 
En el bulevard de Gógol se pueden comprar a módicos precios tulipanes y rosas que han florecido en Bulgaria o en la periferia de Moscú. Luego de un baño de vapor como Dios recomienda en la sauna del Complejo Obrero-Deportivo del centro y con flores en la mano, la sonrisa más franca y Olia: lindísima colgada de tu brazo - porta dos botellas del mejor champán, otra de la mejor vodka y tres del peor vino blanco; camuflageadas en el interior de su bolso y a buena distancia de las miradas indiscretas, pues, La Ley Seca Rusa no resulta una broma más. Aguardamos como dos novios impacientes frente a las cámaras que ahora fueron sustituidas por una puerta, la puerta cerrada del nuevo apartamento del buen Nikita. Se ha casado, dos años atrás, con una muchacha hacendosa de Járkov, Ucrania. Se abre la puerta y una mujer obesa, de rostro tosco y grasoso destruye el encanto. Es fea. La observas una vez más y es horrible. Tal vez con la costumbre, el trato, el corazón te haga cambiar de opinión -piensas. Olia y tú se miran; le preguntan por el paradero de Nikitushka- ya que La Comandanta no les invita a entrar.

-Nikita no está, vendrá dentro de poco. ¿Usted debe ser?... Extendiendo una mano, una mano cual un puente infinito, un país, invitándolos a pasar.

Constituye una casa tragicómica devorada por los objetos. Resulta la cosificación general. Se compran objetos, se venden, se regalan, se piden; se desean. El carnaval de la posesión, los seres absorbidos por la venta, la compra, la liquidación. Al centro los objetos multiplicados, almacenados, coleccionados sin ton ni son... La gran peste del consumismo que no los deja pensar. El oro se ríe, bosteza, niega, se niega frente a tú cara en la boca de todos o incluso la mujer de Nikita de manera amarga -no Gorki el escritor, aunque gorki en ruso literal es amargo. Aquellas cabezas danzando fueras de sí, en otro mundo y sin control daban miedo. Nikita no existe, ha dejado de respirar y por las figuras del empapelado en la pared, precisamente en la pared los tapices con un pesado sable gurda tártaro, el acorazado y un castillo. ¡El acorazado y el castillo, un día de Octubre! ¿para qué? -Te dices interiormente con los ojos clavados en la pared: y pensar que prefería lo natural, construir nidos en las plazas, los parques, sembrar árboles... Allí, y no es Nikita por el empapelado tradicional y conservador de aquella pared.

-Es la hija de un alto funcionario, un capote bien colocado en Járkov, hermanito... -Explica desde un diván alegre poco después del regreso, mientras ella y Olia cuchichean y canturrean en la cocina.

- ¡Hermanito, cómo ves desgraciadamente nada nos falta, somos unos bagatyres! Con uno de esos gestos plenos de equivocada felicidad e inimaginables en un asiático de Tartaria.

Desde el principio nada ha sido nunca y a veces sólo mediante la sátira, el ridículo, uno se explica o trata de explicarse ciertas actitudes o lo que es lo mismo: Imposibles, lo utópico. Los pueblos trágicos son muy irónicos, poseen mucho humor acumulado; una real defensa ante los embates de las proposiciones contemporáneas. A la derecha, a la izquierda bagatelas absurdas. Cosificación que le impide a la humanidad pensar con libertad. ¿Y el Nikitushka aquél, él otro, dónde andará? Observas los tulipanes, las rosas imponentes en unos jarrones chinos de porcelana, unos mings legítimos. Los tapices, las alfombras, y es imposible trasladar la terminología exacta a la realidad. Nikita se ha convertido en Vanka Kain, miras los iconos de perspectiva inversa, sin sonrisas en la pared y piensas: "Tal vez Dios lo 
absuelva, pero los hombres, los humanos..., jamás". Bebimos aquellas botellas y otras que por arte de magia el anfitrión fue trayendo de su surtida despensa.

Aquel fin de semana recordamos nuestros anteriores encuentros y no pudimos recobrarnos del asombro, ni de la borrachera de aquellos días. El lunes bien temprano Olia y tú abandonaron el museoapartamento del tártaro Nikita, convencidos de que no habría retorno y además: ya desde entonces Nikita el poderoso se preparaba para los cambios, las transformaciones que vendrían. Crujía y nos dolía como si fuera un volcán la cabeza, en fin, no teníamos cabezas y tomándola con suavidad por la cintura a la manera parisina que para el puritanismo moscovita resulta un sacrilegio, le digo con dulzura al oído:

-Creen llegar a la verdad por el camino de las apariencias... ¡Pobre Nikita, ha perdido completamente el juicio!

Al parecer por el gesto que realizó no ha comprendido, y es que existen épocas, momentos en los cuales los hombres de talento pueden fracasar por ser los primeros en hallar algo nuevo y expresarlo.

-¡No jodas, mi negrito! Me dijo Olia dándome un cariñoso carterazo en el costado.

Olia es como ya se dijo la más humilde y hermosa mujer que como cualquiera en el crudo invierno necesita sobre ella, sepa usted, sentir una pasión bestial.

Caía la noche en su desnudez y nos besamos con intensidad bajo los fanales.

Hace tres meses que no sabemos nada de Nikita, ni de su esposa. Nikita tal vez tuvo razón en comentar: "iLas mujeres rusas son vulgares y tediosas campeón, es cosaca, una aldeana del centro y por dentro una formidable guerrera, te pesará, acuérdate de mí entonces, haragán!”. Reflexionas, mientras en la Avenida los claxon languidecen. El buen Nikitushka se unió a una chica obesa ucraniana. Olia, cosaca, guerrera al fin, me abraza sin pronunciar palabras protegiéndome de cualquier mal. Yo medito sobre la situación grotesca del buen Nikita. Llegamos al albergue y jamás se lo comenté.

\section{2}

La suerte desata los diversos hilos de la noche, desde el cupé no existen secretos -te dices. Los sauces, los abetos y las huellas fuertes en la nieve de las botas rusas por cada parte. Te hacen recordar la palabra zuka. Así, desde la visita que le hicieron a la fortaleza de Nikita, se refieren Olia y tú; a la mujer. Zuka, es perra -como en español existen perras buenas y perras malas, así lo solemos utilizar. Para ustedes también quiere decir: "Enorme, gigantesca, descomunal, ruda, torpe, rustica, zafia, bruta, salvaje, burda, basta, villana, vulgar, ordinaria, etcétera”. Pero quien ahora te dice: ¡Perra, mono feo del sur!, y te empuja con una fuerza equivalente a cuatro caballos, al final de una extensa cola y lejos de la garita de ventas de boletos o billetes de pasajes de tren, es un ruso monumental que nada dice después, ni la menor disculpa.

Luego se lo devora el aire, la masa eslava de la cual había surgido momentos antes. Olia obsesiva sobre ti: “AAmor, tiíto, los cosacos del Don, sus stanitsas, sin ellos no es posible comprender el 
verdadero espíritu ruso!”. Observas el paisaje a medida que el tren lo devora en sus kilómetros, parajes nocturnos, plateados. Convencido viajas al mínimo país de Olia. En su aldea vas a conocer a las gentes y al mismísimo Don con tus ojos... ¿Acaso no bastan los dones y los cosacos ebrios de Shólojov? ¡Madrecita Rusia, te miro y te quiero, te admiro y adoro, no me canso de mirarte! Los árboles a los lados de la línea férrea asemejan soldados en perfecta formación. Nosotros dos de polizontes, en un convoy militar de mercancías, viajando de paso al Sur, a la Chernoziom -las tierras negras cosacas-, ya que los trenes de pasajeros no se detenían allí.

Un camino metálico grisblanco que no parece concluir nunca, bajo la escama brillante de mis pies cansados... Mi grieta.

-El pez se sala y se cuelga a la intemperie. ¡Tiíto!, y luego es el mejor acompañante del vodka, no se puede comparar ni con el caviar, ni el queso blanco, ni con nadie que para hacer pareja con el vodka, vuelvo y le repito, es lo mejor. Oiga aguilucho, usted no es y no será un bebedor, por lo tanto escúcheme bien, beba y cállese de una buena vez que es lo mejor. -Ordena el padre de Olia, ebrio completamente y colocando su manaza en tu hombro:

-¡Beba que hace frío tiíto aquí, bebamos por la puta Madrecita Rus! -agrega feliz.

-¡Hola! ¡Así me gustan los hombres! - dijo Basilio Andreievish algo achispado, al ver como su futuro yerno bajaba una jarra de medio cuartillo de vodka y la tiraba luego al suelo donde quedó hecha añicos.

Buscas la salvación en los ojos inteligentes de Olia, pero ella conversa muy animada y risueña con su madre, mientras preparan un gran banquete: Salade a la Russe, Studines, el puré de patatas con salchichas, queso y mantequilla. Shaslik -trocitos de carnero asados en brochetas-, salchichones solos y en salsa, caviar, salmón, y el té, porque en una generosa mesa eslava no debe faltar; con los panecillos aparte que humean como el agua en el samovar.

-¡Te gusta más que el Kvas mi rusalka sureño -dijo atrayendo hacia sí a su hija y continúo: es hermosa como mis yeguas, extranjero!

El campo del Don. Las isbushkas sin tonalidades, los colores contenidos y el cielo desbordado, rojizo, nada de ruidos. Los monasterios de maderas preciosas y las doradas cúpulas que asemejan envolturas de caramelos. Los popes con su religión por los senderos majestuosos y escondidos. Los crepúsculos del manzano en flor en los ojos de Olia -cosas que ves y no ves: las presientes; imágenes que no paran de admirarse. Flores, verdor, cucos, ruiseñores y tortolillas. Fue un verano anterior y más tarde el invierno o será el próximo. Un camino nevado con tarjas recordándonos: aquí yace un hombre y lo efímera de nuestra existencia. Un verano nos bañaremos en el río que sustituye las amplias playas de mar. Después en el mismo río helado miles de hombres hacen sus orificios y pescan.

-No me agrada la ciudad, tiíto..., el electrishka o electrishcheski a miles de verstás de las tierras negras, no me entusiasman los fanales vertiendo sus luces de neón de mala muerte sobre el pavimento recto. La ciudad de las millones de puertas dormidas, en apariencia, ruidosa aún en exceso, uno despierto mirando el cielo nocturno y las estrellas no se dejan ver entre tantos obstáculos y no me gusta 
observar así al cielo. ¡Qué lindo! verdad, ¿mi Lisavetka? -Repite risueño las frases hacia su esposa. Por Amour... ¡Mira a mi pajarito con una pajilla del sur en el pico! Expresa como afirmándose él mismo.

La borrachera in crescendo de ustedes y la dasha de toscas piedras. Sucede como en las fabulas antiguas rusas que se confunden con las nórdicas, las polacas, letonas, las ucranianas. Los iconos en el Kivot girando. Los caballos saben por intuición reconocer el sendero. En La Habana tirado en el carretón que guía La Niña viene borracho el abuelo, coronel de la última guerra de independencia contra los españoles. La abuela no lo ve y grita de dolor movilizando al vecindario, hasta que en el filo de la carreta aparece la cabeza bebida, risueña del abuelo.

-“Los caballos piensan”. -Solía decir. ¡Esta Mujer! Mirando con cariño indescriptible a la abuela.

-Más inteligentes que las mujeres son los caballos, aguilucho -confiesa el padre de Olia, guiñándote el ojo y prosigue: Mi Paulishka es la potranca más lógica y fiel del mundo, siempre me trae desde el Koljos, no la cambio ni por el Samara del año.

Eran dos yeguas que a miles de kilómetros realizaban la misma función, lo extraño del caso es que pertenecían al género femenino y nunca se te ha acercado nadie para decir que su caballo es un genio.

Hacia el norte se hallan los bosques vírgenes y se extienden millones de verstás hasta Siberia Oriental. En la Siberiada Absurda los leñadores cubanos. Sobre la ribera se puede ver el Don apacible congelado, el esqueleto semicubierto en el río de un remoto embarcadero.

-Allí vienen, arribaban las balsas, los botes, las lanchas rebosantes de plateados peces. Esos peces de oro -lo escuchas tararear... Y no son peces, Basilio Andreievish, son pescados. Lo sabe el viejo Santiago, cuando un pez, luego de heroica lucha, descansa muerto, atrapado en la superficie del bote, entonces ya no es un pez es un pescado.

Basilio Andreievish posee los ojos grisazulados y el cabello pelirrojo -ahora entrecano, diminuto. Los pies como las manos son enormes, fuertes y camina oscilando con rareza de oso. La nariz es bella, recta. Es la misma nariz que besas, adoras y mimas cada mañana en Olia. En Rusia, es menos frecuente la nariz recta que el pie. Basilio pide que lo beses a la rusa. Un beso en la boca, sin erotismo alguno, sin lo libido de la lengua, pero resulta un beso labio con labio y sonoro. El beso, la unión máxima de dos borracheras que se reconocen, se solidarizan y se respetan. El beso de la amistad eterna rusa, la familiaridad.

El beso, un beso y no temas. Olia a la noche junto a ti, en ti y sobre las sábanas bordadas con motivos cosacos que nos regaló su madre, constituye otro sueño ruso que no se acaba. Pues el amor necesita complicidad y silencio; somos dioses cuando nos amamos. Partículas cargadas de espíritu dispuestas a soñaramar.

-¡Tí́to, haz feliz a mi Olga! -Pide Basilio Andreievish enredado en su propio cuento. Un nudo se forma en medio de la garganta y no te permite articular sonidos. Reconoces que la palabra de orden es: Casamiento, Matrimonio.

Enlace. Prefieres conversar en español para desterrar tu honor. Hacerte-literalmente- el loco. 
Las flores se venden y se compran por doquier. Por la ventanilla abierta del cupé compras un ramo de flores rojas para Olia, otro de girasoles portentosos para Lisaveta. A su vez Lisaveta, te regala una Shuba -camisa típica bordada a lo cosaco festivo y con un solo botón de oro en el cuello. Basilio Andreievish con brusquedad y antes de que comience a moverse el tren, logra sacar tu cabeza por la ventanilla del coche y te besa a la rusa: una, dos, tres, miles de veces, te empapas en vodka, ajos y cebollas del Don. El aliento etílico de tu suegro sella el conteo; llueven los besos cosacos, los baboseos familiares, inundan como el vodka, cual brindis en el país legendario de nunca acabar. 


\section{Glosario}

Bagatyr o Bagatyres: héroe(s) de la épica rusa, forzudo guerrero o persona rica; pudiente.

Dasha: edificación de descanso o veraneo típicamente eslava, o casa de campo en las afueras de las ciudades y que incluye huerta. Las dashas más famosas se encuentran en las afueras de Moscú, se hallan en la aldea de los escritores en Peredélkino. Ahora les doy esta perlita hallada en el Diccionario Oxford ruso-inglés de Marcus Wheeler. Dasha: casita de veraneo en el campo, en los alrededores de una ciudad o de una población grande.

Electrishka o electrishcheski: tren de pasajeros interurbano.

Feedor: confesor de su majestad el Zar Pedro I o Pedro el Grande de Rusia.

Isbushkas: diminutivo de Isba, cabaña o casa de madera en las aldeas campesinas eslavas.

Kivot o Kiot: especie de altar o urna donde se colocan los santos y dioses -íconos- en la iglesia ortodoxa rusa.

Kvas: bebida refrescante típica rusa fermentada a base de pan de centeno que carece de alcohol.

Popes: sacerdotes de la iglesia ortodoxa rusa, el más famoso en Rusia resulta el Pope.

Rusalka: ninfa de las aguas en la mitología eslava.

Samara: nombre de una ciudad rusa, ubicada al este del río Volga y que designa un automóvil que allí se construye.

Stanitsa: pueblo de cosacos en el Sur de Rusia, en la actual Ucrania.

Vanka Kain: jefe de la policía durante el reinado de Catalina II. Ladrón, soplón y confidente con anterioridad.

Verstás: antigua medida rusa equivalente a 1,06 kms. Con este término el pueblo ruso se refiere a la leyenda de que Pedro I, el Zar carpintero y navegante, trazó San Petersburgo con una regla y así fue edificada por los arquitectos italianos, por lo que la ciudad resulta totalmente plana y recta. 